\title{
Development of a real-time PCR assay for identification and quantification of the fish pathogen Francisella noatunensis subsp. orientalis
}

\author{
Esteban Soto ${ }^{1}$, Kimberly Bowles ${ }^{2}$, Denise Fernandez ${ }^{1}$, John P. Hawke ${ }^{1, *}$ \\ ${ }^{1}$ Department of Pathobiological Sciences and ${ }^{2}$ Louisiana Animal Disease Diagnostic Laboratory, School of Veterinary \\ Medicine, Louisiana State University, Skip Bertman Dr., Baton Rouge, Louisiana 70803, USA
}

\begin{abstract}
Members of the genus Francisella are small Gram-negative facultative intracellular bacteria that cause francisellosis in a wide variety of fish species worldwide. F. noatunensis subsp. orientalis has been recently described as a warm-water pathogen of tilapia Oreochromis spp. In this study, a quantitative real-time polymerase chain reaction (qPCR) TaqMan probe assay was developed to rapidly and accurately detect and quantify $F$. noatunensis subsp. orientalis from fish tissue. The target region of the assay was the F. tularensis iglC gene homologue previously found in F. noatunensis subsp. orientalis. Probe specificity was confirmed by the lack of signal and cross-reactivity with 12 common fish pathogens, 2 subspecies of F. tularensis, F. noatunensis subsp. noatunensis, and tilapia tissue. The range of linearity was determined to be $50 \mathrm{fg}$ to $1.4 \mathrm{mg}$, and the lower limit of detection was $50 \mathrm{fg}$ of DNA (equivalent to $\sim 25$ genome equivalents) per reaction. A similar sensitivity was observed with DNA extracted from a mixture of F. noatunensis subsp. orientalis and fish tissue. The assay was also able to detect and quantify F. noatunensis subsp. orientalis from the spleens of experimentally infected tilapia. No signal was observed in the control groups. In conclusion, we have developed a highly sensitive and specific assay that can be used for the specific identification and quantification of $F$. noatunensis subsp. orientalis.
\end{abstract}

KEY WORDS: Francisella $\cdot$ Tilapia $\cdot$ qPCR

Resale or republication not permitted without written consent of the publishe

\section{INTRODUCTION}

Francisellosis is an emergent disease in fish caused by Gram-negative facultative intracellular bacteria that are members of the genus Francisella. In tilapia the disease can be observed as an acute syndrome with few clinical signs and high mortality, or as a subacute to chronic syndrome with non-specific clinical signs like anorexia, exophthalmia, and anemia. Upon macroscopic and microscopic examination, internal organs are enlarged and contain widespread multifocal white nodules. Histological examination often reveals the presence of multifocal granulomatous lesions, with the presence of numerous small, pleomorphic, cocco-bacilli (Hsieh et al. 2006, Mauel et al. 2007, Soto et al. 2009a).
During the past 5 yr, bacteria of the genus Francisella have caused significant mortalities in cultured tilapia Oreochromis spp., Atlantic cod Gadus morhua, Atlantic salmon Salmo salar L., hybrid striped bass Morone chrysops $\times$ M. saxatilis, three-line grunt Parapristipoma trilineatum, and ornamental cichlids, both in warm- and cold-water environments (Kamaishi et al. 2005, Nylund et al. 2006, Olsen et al. 2006, Ostland et al. 2006, Birkbeck et al. 2007, Hsieh et al. 2007, Mauel et al. 2007, Mikalsen et al. 2007, Ottem et al. 2007, Soto et al. 2009a).

The identification and taxonomic characterization of the Francisella spp. identified as worldwide emerging pathogens of fish have been difficult owing to the fastidious nature of the bacteria and the small number of isolates recovered from fish (Soto et al. 2009a). In the majority of the cases, PCR and sequence comparison of 
the 16S rRNA have made it possible to place the organisms at $97 \%$ similarity to $F$. tularensis, $98 \%$ similarity to F. philomiragia, and $99 \%$ to other Francisella spp. strains isolated from fish species (Kamaishi et al. 2005, Hsieh et al. 2006, Ostland et al. 2006, Mauel et al. 2007, Mikalsen et al. 2007, Ottem et al. 2007, Soto et al. 2009a). The Francisella strain utilized in this research project at the Louisiana Aquatic Diagnostic Laboratory, LSU School of Veterinary Medicine, LADL 07-285A, isolated from tilapia Oreochromis spp. from Costa Rica, was confirmed by molecular analysis as $F$. noatunensis subsp. orientalis (Soto et al. 2009a) and exhibited 99\% identity with $F$. noatunensis subsp. noatunensis isolated from diseased Atlantic cod in Norway (Euzéby 2009, Ottem et al. 2009), by sequence comparison of the $16 \mathrm{~S}$ rRNA. The LADL 07-285A and 07-285B isolates used in this study also belong to the same group described as F. asiatica (Mikalsen \& Colquhoun 2009); however, this name does not yet have valid taxonomic standing (J. Euzéby pers. comm.).

The diagnosis of this highly virulent fish pathogen has many constraints, including the fastidious nature of the bacterium and the lack of biochemical, molecular, and serological tests specific for this aquatic animal pathogen. Previous diagnosis of francisellosis in fish species has been made with the aid of histopathology, electron microscopy, conventional culture assays, conventional polymerase chain reaction (PCR) using Francisella sp. specific primers, 16S rRNA sequencing, and in situ hybridization (Kamaishi et al. 2005, Hsieh et al. 2006, Ostland et al. 2006, Mauel et al. 2007, Ottem et al. 2007, Soto et al. 2009a). However, the diagnosis of the pathogen remains a challenge, and some of the current techniques are difficult, time consuming, and expensive; some require specialized personnel and are prone to show false negatives because of low sensitivity, or false positives because of low specificity. Moreover, studies with F. tularensis have shown that diagnosis based on isolation by culture is prone to show false-negative results (Fujita et al. 2006).

Real-time PCR is a well known molecular technique that is currently used in many laboratories for diagnosis of microbial pathogens, including the fastidious bacteria Mycobacterium spp., Bacillus anthracis, Francisella tularensis, and organisms that are non-culturable on cell-free media, the Rickettsia spp. and viruses (Bode et al. 2004, Kocagoz et al. 2005, Takahashi et al. 2007, Tomaso et al. 2007, Abril et al. 2008, Kidd et al. 2008). In recent years, fish disease diagnosticians have used this technique to identify and quantify bacterial, viral, and parasitic fish pathogens such as Aeromonas salmonicida, Flavobacterium columnare, Renibacterium salmoninarum, Henneguya ictaluri, largemouth bass virus, and recently Francisella piscicida in Norwegian cod (Balcázar et al. 2007, Getchell et al. 2007,
Panangala et al. 2007, Suzuki \& Sakai 2007, Griffin et al. 2008, Ottem et al. 2008). The high sensitivity, high specificity, and short turnaround time for results make this technique an attractive replacement method for conventional diagnostic techniques (Espy et al. 2006).

The genes of the intracellular growth locus (iglA, $i g l B$, iglC, and $i g l D$ ) are some of the most interesting genes identified in the genus Francisella. These genes are present as part of a $30 \mathrm{~kb}$ pathogenicity island described by Nano et al. (2004) and Barker \& Klose (2007) in Francisella tularensis. The Francisella pathogenicity island (FPI), a cluster of 16 to 19 genes, has been found duplicated in some $F$. tularensis genomes, but as a single copy in the $F$. philomiragia subsp. philomiragia ATCC 25015 isolate, a close relative of the tilapia pathogen $F$. noatunensis subsp. orientalis strain LADL 07-285A (Nano \& Schmerk 2007, Soto et al. 2009b).

The functions of the conserved proteins corresponding to the genes are elusive. Overall, Igl proteins appear to be essential for the ability of Francisella tularensis to survive inside the macrophage and cause disease (Golovliov et al. 1997, Lai et al. 2004, Lauriano et al. 2004, Nano et al. 2004, Santic et al. 2005, Brotcke et al. 2006, de Bruin et al. 2007). Homologues of the F. tularensis iglABCD genes in the tilapia pathogenic F. noatunensis subsp. orientalis strain LADL 07-285A were identified and described in a previous study (Soto et al. 2009b). The presence of a single iglC gene in the completely sequenced and closely related isolate $F$. philomiragia subsp. philomiragia ATCC 25017 suggests that the gene is also present in single copy in F. noatunensis subsp. orientalis strain LADL 07-285A. The presence of a single copy of the iglC gene in $F$. noatunensis subsp. orientalis makes the gene an excellent target for developing a highly specific diagnostic test and will provide a means to quantify with a high degree of confidence the amount of bacterial DNA present in a sample.

The aim of this study was to develop a quantitative real-time PCR assay using the previously described iglC gene of the fish pathogen Francisella noatunensis subsp. orientalis as a target. We describe a highly sensitive, specific, and reliable molecular diagnostic technique for identification and quantification of $F$. noatunensis subsp. orientalis from diseased fish.

\section{MATERIALS AND METHODS}

Bacterial species and strains. The bacterial strains used in this project were chosen because they represent common bacterial fish pathogens, or are members of the genus Francisella. Strain LADL 07-285A, isolated from diseased cultured tilapia Oreochromis 
spp. was chosen as a representative of the warmwater strain of fish pathogenic $F$. noatunensis subsp. orientalis. The majority of the isolates tested were recovered by the Louisiana Aquatic Diagnostic Laboratory (LADL), in the School of Veterinary Medicine (LSU-SVM) at Louisiana State University, from diseased fish, while others were acquired from the American Type Culture Collection (ATCC). F. tularensis subsp. novicida U112 and F. tularensis subsp. holarctica (LVS isolate) DNA were kindly donated by Dr. Bernard Arulanandam and Dr. Jieh-Juen Yu, from the Department of Biology, University of Texas at San Antonio. F. noatunensis subsp. noatunensis is a recently described member of the genus Francisella isolated from farmed Atlantic cod displaying chronic granulomatous disease (Mikalsen et al. 2007, Mikalsen \& Colquhoun 2009, Ottem et al. 2009) and was kindly donated by Dr. Anne-Berit Olsen, National Veterinary Institute, Bergen, Norway. Francisella isolates 1, 2, and 3 recovered from moribund hybrid striped bass (Ostland et al. 2006) and F. victoria recovered from tilapia (Kay et al. 2006) and showing >99\% identity with $F$. noatunensis subsp. orientalis after $16 \mathrm{~S}$ rDNA sequence comparison were kindly donated by Dr. John Hansen, Interdisciplinary Program in Pathology, University of Washington, Seattle, WA, USA. Following previously published molecular techniques and protocols (Soto et al. 2009b), PCR and sequence comparison of the $i g l A B C D$ operon (Appendix 1, Figs. A1
\& A2) and 16S rDNA sequences, as well as phenotypic characteristics, temperature requirements, and host range analysis, demonstrated that isolated Francisella sp. 1, Francisella sp. 2, Francisella sp. 3 (Ostland et al. 2006), and F. victoria (Kay et al. 2006) are in fact members of the recently described species $F$. noatunensis subsp. orientalis (Figs. A1 \& A2) (Soto et al. 2009b). F. noatunensis subsp. orientalis strain LADL 07-285A was grown in cystine heart agar with hemoglobin (CHAH) supplemented as outlined by Soto et al. (2009a) for $48 \mathrm{~h}$ at $28^{\circ} \mathrm{C}$. F. noatunensis subsp. noatunensis was grown in a similar manner but was incubated at $20^{\circ} \mathrm{C}$ for $5 \mathrm{~d}$. Flavobacterium columnare was grown on dilute Mueller Hinton agar for $48 \mathrm{~h}$ at $28^{\circ} \mathrm{C}$. Mycobacterium marinum and Nocardia seriolae were grown on Lowenstein Jensen slants for $1 \mathrm{wk}$ at $28^{\circ} \mathrm{C}$. All the other bacteria used in the study were grown on blood agar (BA) $5 \%$ sheep blood plates for $48 \mathrm{~h}$ at $28^{\circ} \mathrm{C}$. The complete list of the isolates used in this study is shown in Table 1.

Template DNA preparation. Bacterial cultures grown on agar media were suspended in $1 \mathrm{ml}$ of $1 \mathrm{X}$ phosphate-buffered saline (PBS), and $200 \mu \mathrm{l}$ were used for nucleic acid isolation following the manufacturer's protocol in the High Pure PCR Template Preparation Kit (Roche Diagnostics). Nucleic acid was also extracted from a negative control consisting of $1 \mathrm{X}$ sterile PBS alongside of the unknowns to ensure no crosscontamination occurred during the extractions.

Table 1. Bacterial DNA used in the present study. qPCR: quantitative real-time PCR; a negative $(-)$ threshold cycle $\left(C_{t}\right)$ value represents no logarithmic amplification detected within 40 amplification cycles. ATCC: American Type Culture Collection; LADL: Louisiana Aquatic Diagnostic Laboratory, Louisiana State University School of Veterinary Medicine; NVI: National Veterinary Institute, Bergen, Norway; UTSA: Dept. of Biology, University of Texas at San Antonio; UW: University of Washington

\begin{tabular}{|c|c|c|}
\hline Bacteria species & Source & qPCR result \\
\hline Francisella noatunensis subsp. orientalis isolate LADL 07-285A & Tilapia Oreochromis spp., LADL & + \\
\hline Francisella noatunensis subsp. orientalis isolate LADL 07-285B & Tilapia Oreochromis spp., LADL & + \\
\hline Francisella noatunensis subsp. orientalis Strain 1 & Hybrid striped bass Morone chrysops $\times$ M. saxatilis, UW & + \\
\hline Francisella noatunensis subsp. orientalis Strain 2 & Hybrid striped bass Morone chrysops $\times$ M. saxatilis, UW & + \\
\hline Francisella noatunensis subsp. orientalis Strain 3 & Hybrid striped bass Morone chrysops $\times M$. saxatilis, UW & + \\
\hline Francisella noatunensis subsp. orientalis 'F. victoria' & Tilapia nilotica Oreochromis niloticus, UW & + \\
\hline Francisella noatunensis & Atlantic cod Gadus morhua L., NVI & - \\
\hline Francisella tularensis subsp. novicida U112 & UTSA & - \\
\hline Francisella tularensis subsp. holarctica LVS & UTSA & - \\
\hline Edwardsiella tarda & Tilapia Oreochromis spp., LADL & - \\
\hline Edwardsiella ictaluri (ATCC 33202) & Channel catfish Ictalurus punctatus & - \\
\hline Photobacterium damselae subsp. piscicida (ATCC 17911) & White perch Roccus americanus & - \\
\hline Aeromonas hydrophila & LADL & - \\
\hline Aeromonas salmonicida & LADL & - \\
\hline Streptococcus iniae (ATTC 29177) & Amazon freshwater dolphin Inia geoffresis & - \\
\hline Streptococcus agalactiae & Tilapia Oreochromis spp., LADL & - \\
\hline Flavobacterium columnare (ATCC 23463) & Chinook salmon Oncorynchus tshawytscha & - \\
\hline Vibrio anguillarum & Hybrid striped bass Morone chrysops $\times M$. saxatilis, LADL & - \\
\hline Vibrio mimicus & Crayfish Procambarus clarkii, LADL & - \\
\hline Mycobacterium marinum & Florida pompano Trachinotus carolinus, LADL & - \\
\hline Nocardia seriolae & Pompano Trachinotus blochii, LADL & - \\
\hline
\end{tabular}


TaqMan primers and probe. The TaqMan primers and probe used in this study were designed on the basis of the nucleotide sequence comparison of the iglC gene of Francisella tularensis subsp. novicida U112 iglC (GenBank Accession number AY293579), F. tularensis subsp. holarctica FTNF002-00 iglC (GenBank Accession number CP000803), F. tularensis subsp. mediasiatica FSC147 iglC (GenBank Accession number CP000915), F. philomiragia ATCC 25017 iglC (GenBank Accession number CP000937), and F. noatunensis subsp. orientalis LADL 07-285A iglC (GenBank Accession number FJ386388) (Table 2). The primers and probe were designed following the realtime qPCR Assay Design Software (Biosearch Technologies). Primers and probe concentration were optimized at the beginning of the study to determine the minimum primer concentrations giving the maximum change in the normalized reporter dye fluorescence $(\Delta \mathrm{Rn})$, and the minimum probe concentration that gave the minimum threshold cycle $\left(C_{\mathrm{t}}\right)$. The optimization was done according to the TaqMan Universal PCR Master Mix manufacturer (Applied Biosystems).

Real-time TaqMan PCR assays. The real-time PCR assays were conducted and analyzed within the Applied Biosystems 7500 Fast Real-Time PCR Systems (Applied Biosystems). The $25 \mu \mathrm{l}$ reaction mixture consisted of a TaqMan Universal PCR Master Mix (Applied Biosystems), containing $10 \mathrm{pmol}$ of each primer, 3 pmol of probe, and $5 \mu$ of DNA extracted sample. Template controls containing PCR grade water and

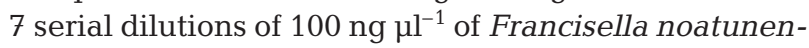
sis subsp. orientalis isolate LADL 07-285A diluted in PCR grade water and measured in a NanoDrop Spectrophotometer ND-1000 V3.5 (Nanodrop Technologies) were included in each run.

The unknown samples, as well as the diluted standards and negative controls, were run in triplicate. Cycling conditions were $2 \mathrm{~min}$ at $50^{\circ} \mathrm{C}, 15 \mathrm{~min}$ at $95^{\circ} \mathrm{C}$ followed by 40 cycles of $15 \mathrm{~s}$ at $95^{\circ} \mathrm{C}$, and $60 \mathrm{~s}$ at $60^{\circ} \mathrm{C}$.

Sensitivity of the real-time PCR assays: For sensitivity determination, the TaqMan assays were evaluated by 2 different independent methods. Three separate extractions of Francisella noatunensis subsp. orientalis DNA were adjusted to a concentration of $100 \mathrm{ng}^{-1}$

Table 2. TaqMan primers and probe used in the present study. FAM: 6-carboxy-fluorescein; BHQ-1: black hole quencher 1

\begin{tabular}{|lcc|}
$\begin{array}{l}\text { Primers and } \\
\text { probe }\end{array}$ & $5^{\prime}-3^{\prime}$ sequence & $\begin{array}{c}\text { Melting } \\
\text { temp. }\left({ }^{\circ} \mathrm{C}\right)\end{array}$ \\
\hline iglC forward & gggcgtatctaaggatggtatgag & 66.36 \\
iglC reverse & agcacagcatacaggcaagcta & 66.63 \\
iglC probe & FAM atctattgatgggctcacaacttcacaa BHQ-1 & 68.34 \\
\hline
\end{tabular}

NanoDrop Spectrophotometer ND-1000 V3.5 (Nanodrop Technologies), and 10-fold dilutions were made in PCR grade water until they reached a concentration of $1 \mathrm{fg} \mathrm{Hl}^{-1}$. Genome equivalent (GE) calculation was based on assuming a 2-MB genome size for F. philomiragia and several subspecies of $F$. tularensis (Takahashi et al. 2007, Tomaso et al. 2007, Abril et al. 2008, Ottem et al. 2008). For determination of colonyforming units (CFU), several isolated colonies of $F$. noatunensis subsp. orientalis were picked from a fresh $\mathrm{CHAH}$ culture and suspended in $1 \mathrm{ml}$ of PBS at $\mathrm{pH} 7.2$, until an optical density $(\mathrm{OD})_{600}$ of 0.75 was reached and measured in a DU-640 Spectrophotometer (Beckman Coulter). Ten-fold serial dilutions in PBS were made from this sample, and colony counts were performed on $\mathrm{CHAH}$ by the drop plate method to verify bacterial numbers. Extraction of DNA from $200 \mu \mathrm{l}$ of each dilution was used for CFU quantification in the real-time PCR assay. Amplification efficiencies were determined, and all assays were run in triplicate.

Sensitivity of the real-time PCR assay in fish spleen: In order to determine the sensitivity limit of the assay, triplicate samples of $1 \mathrm{~g}$ of uninfected tilapia spleen (recently acquired fresh tissue) were homogenized with a Kontes PELLET PESTLE® Micro Grinder (A. Daigger) in a $4 \mathrm{ml}$ suspension of early stationary phase Francisella noatunensis subsp. orientalis cells diluted in PBS to a final concentration of $2,20,200,2 \times 10^{3}, 2 \times 10^{4}, 2 \times$ $10^{5}, 2 \times 10^{6}, 2 \times 10^{7} \mathrm{CFU} g$ tissue $^{-1}$. A total of $200 \mu \mathrm{l}$ of the homogenates containing approximately $50 \mathrm{mg}$ of spleen were centrifuged at $12000 \times g$ for $1 \mathrm{~min}$ and DNA extracted following the manufacturer's protocol 'Isolation of Nucleic Acids from Mammalian Tissue', High Pure PCR Template Preparation Kit (Roche Diagnostics). Enumeration of $F$. noatunensis subsp. orientalis by real-time PCR was compared with plate count values, taking into account dilution/concentration factors due to volumes used in DNA extraction and final elution volumes. Amplification efficiencies were determined, and all assays were run in triplicate.

Experimental infectivity trial. The tilapia fingerlings used during the trial were obtained from a source with no history of Francisella infection, and a sub-sample of the population was confirmed as negative for Francisella bacteria by complete clinical, bacteriological, and molecular analysis as described by Soto et al. (2009a). Fish were maintained at 10 fish $\operatorname{tank}^{-1}$ and fed commercial tilapia feed daily (Burris Aquaculture Feeds, ) at $\sim 3 \%$ fish body wt $\mathrm{d}^{-1}$. The mean weight of the fish was $9.1 \mathrm{~g}$, and the mean length was $18 \mathrm{~cm}$. Three tanks were used per treatment, and 1 tank was used as a control. Fish were immersed in 81 of static water containing approximately $3.7 \times 10^{7}$ 
$\mathrm{CFU} \mathrm{m} \mathrm{l}^{-1}$ in tank water for $3 \mathrm{~h}$ at 23 to $25^{\circ} \mathrm{C}$, and then the volume of the tanks was adjusted to 201 with clean oxygenated water. Control fish were treated in a similar manner but received sterile PBS.

Following each challenge exposure, mortality was recorded every $12 \mathrm{~h}$ for $30 \mathrm{~d}$. Prior to collection of spleen, moribund and survivor fish were euthanized with an overdose of MS-222. The spleens from dead, moribund, and survivor fish were collected aseptically in 1.5 microcentrifuge tubes (Fisherbrand, Fisher Scientific) and weighed, and DNA was extracted from $\sim 20 \mathrm{mg}$ of spleen following the manufacturer's protocol 'Isolation of Nucleic Acids from Mammalian Tissue', High Pure PCR Template Preparation Kit (Roche Diagnostics). The rest of the tissue was homogenized in $\sim 50 \mu \mathrm{l}$ PBS and plated on CHAH. The eluted DNA was stored at $4^{\circ} \mathrm{C}$ until used.

\section{RESULTS}

\section{Specificity}

The assay was found to be specific for the warm-water fish pathogen Francisella noatunensis subsp. orientalis (Table 1), and no evidence of cross-reactivity was detected (no significant elevated signal was observed with any of the other tested bacterial DNA) (Fig. 1).

\section{Sensitivity}

The sensitivity of the assay was determined using a triplicate dilution series from $0.5 \mathrm{fg} \mathrm{reaction}^{-1}$ to $1.4 \mathrm{mg}$ reaction $^{-1}$ of Francisella noatunensis subsp. orientalis

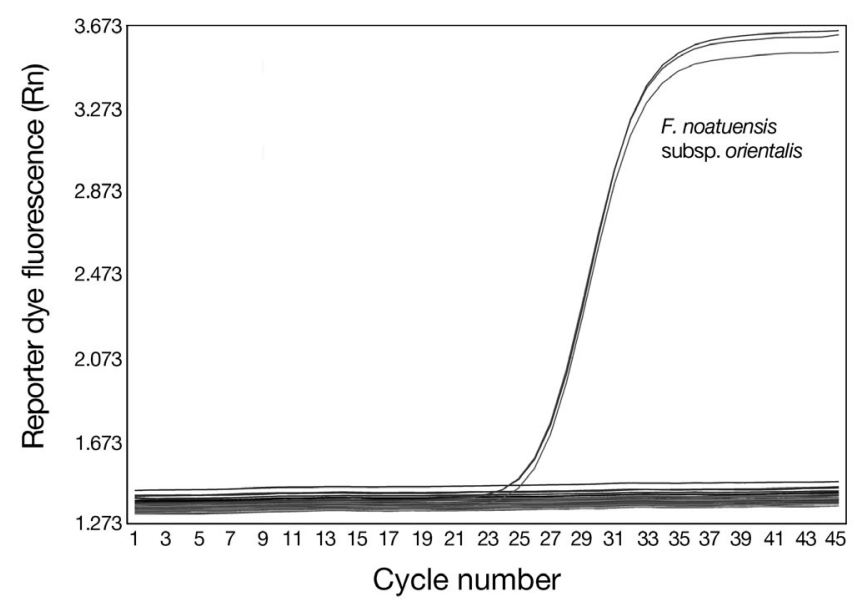

Fig. 1. Detection of the iglC gene by the TaqMan probe realtime PCR assay. A total of $500 \mathrm{pg}$ per reaction of DNA from 21 different strains of fish pathogens or member of the genus Francisella sp. were used. The amplification plot displays normalized reporter dye fluorescence (Rn) as a function of cycle genomic DNA. The lowest amount of detection was determined to be $50 \mathrm{fg}$ DNA (equivalent to $\sim 25 \mathrm{GE}$ ). $C_{\mathrm{t}}$ determined by TaqMan real-time PCR amplification of DNA, extracted from serial dilutions of pure F. noatunensis subsp. orientalis bacterial culture, showed a linear $\left(\mathrm{R}^{2}=0.994\right)$ relationship with $\log$ numbers of CFU from $2.5 \times 10^{7}$ to $2.5 \times 10^{1} \mathrm{CFU} \mathrm{ml}^{-1}$ based on plate counts (Fig. 2). Ten-fold serial dilutions of nucleic acid extracted from the initial dilutions of the pure bacterial culture also showed a linear relationship between the log amount of nucleic acid and the TaqMan real-time PCR $C_{\mathrm{t}}$ from $1.4 \mathrm{mg}$ to $50 \mathrm{fg}$ (Fig. 2). Linear detection of amplified product was also revealed in serially diluted F. noatunensis subsp. orientalis spiked spleen homogenates $\left(\mathrm{R}^{2}=0.985\right)$ (Fig. 2, Table 3$)$. This indicates that the presence of tissue homogenate did not impede the sensitivity of the real-time PCR assay within this range of CFUs. Uninfected tilapia spleen and water controls showed no signal after 40 cycles.

\section{Detection of Francisella noatunensis subsp. orientalis in experimentally infected fish}

At $30 \mathrm{~d}$ following challenge, the mean mortality in the tanks was $56.6 \%$. In order to test the ability of the iglC TaqMan assays to identify Francisella noatunensis subsp. orientalis in tilapia tissue, spleens from infected fish were analyzed. One hundred percent of the

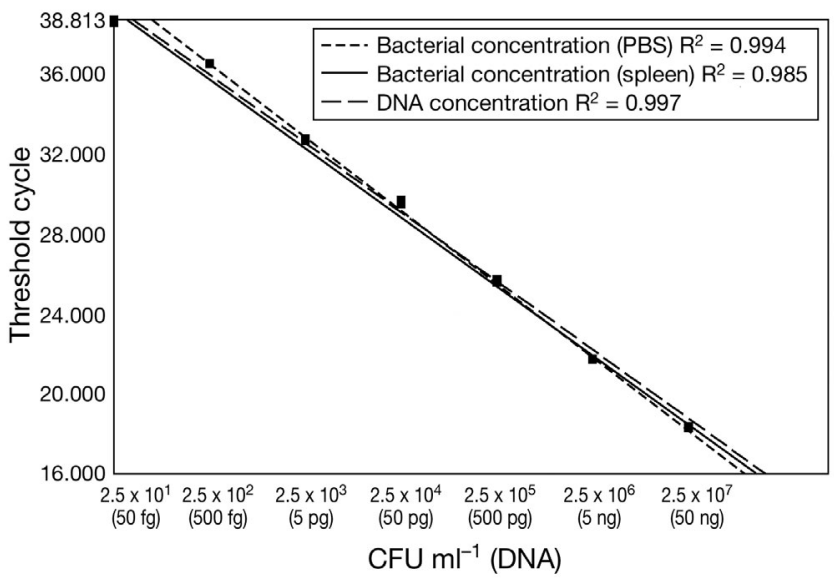

Fig. 2. Francisella noatunensis subsp. orientalis. Standard curve denoting the sensitivity limits of detection with 10 -fold serial dilutions of $F$. noatunensis subsp. orientalis isolate LADL 07-285A DNA, colony-forming units (CFU) added to phosphate-buffered saline (PBS), and CFU added to spiked spleen homogenates. Threshold cycle values plotted against DNA or CFU added to PBS or spleen homogenates ranging from $2.5 \times 10^{1}$ to $2.5 \times 10^{7} \mathrm{CFU} \mathrm{ml}^{-1}$ show a linear correlation of $\mathrm{R}^{2}=0.994$ for CFU in PBS (short-dashed line), $\mathrm{R}^{2}=0.985$ for CFU in spleen homogenates (black line), and $\mathrm{R}^{2}=0.997$ for DNA (long-dashed line). Results are from triplicate samples run simultaneously 
Table 3. Francisella noatunensis subsp. orientalis. Quantification of the pathogen from inoculated phosphate-buffered saline (PBS) and spleen. Colony counts were determined by plate counts on threshold cycle $\left(C_{\mathrm{t}}\right)$ cystine heart agar with hemoglobin (CHAH) plates as described in the 'Materials and methods'. Real-time PCR determination of concentrations was based on the mean of triplicate samples. Concentrations were derived from a standard curve using the mean of triplicate $C_{\mathrm{t}}$ values of serial 10-fold dilutions of DNA extracted from known concentrations of bacteria. CFU: colony-forming units; qPCR: quantitative real-time polymerase chain reaction

\begin{tabular}{|c|c|c|c|c|}
\hline \multirow{2}{*}{$\begin{array}{l}\text { Inoculum } \\
\left(\log \mathrm{CFU} \mathrm{m}{ }^{-1}\right)\end{array}$} & \multicolumn{2}{|c|}{ Colony counts (log CFU ml ${ }^{-1} \pm \mathrm{SD}$ ) } & \multicolumn{2}{|c|}{ Extracted DNA qPCR $\left(C_{\mathrm{t}} \pm \mathrm{SD}\right)$} \\
\hline & PBS & Spleen homogenate & PBS & Spleen homogenate \\
\hline 7.3 & $7.59 \pm 0.061$ & $7.43 \pm 0.13$ & $18.35 \pm 0.028$ & $18.53 \pm 0.228$ \\
\hline 6.3 & $6.62 \pm 0.12$ & $6.69 \pm 0.12$ & $25.70 \pm 0.017$ & $25.12 \pm 0.117$ \\
\hline 5.3 & $5.52 \pm 0.13$ & $5.46 \pm 0.15$ & $29.65 \pm 0.059$ & $29.33 \pm 0.125$ \\
\hline 4.3 & $4.86 \pm 0.12$ & $4.88 \pm 0.12$ & $32.80 \pm 0.112$ & $32.1 \pm 0.134$ \\
\hline 3.3 & $3.59 \pm 0.33$ & $3.5 \pm 0.0 .39$ & $36.54 \pm 0.083$ & $36.74 \pm 0.121$ \\
\hline 2.3 & $2.43 \pm 0.19$ & $2.58 \pm 0.2$ & $38.74 \pm 0.016$ & $38.32 \pm 0.026$ \\
\hline 1.3 & $0.33 \pm 0.35$ & $1.03 \pm 0.43$ & $25.70 \pm 0.118$ & $26.12 \pm 0.418$ \\
\hline
\end{tabular}

morbid and survivor (challenged) fish were positive by the assay, and all non-challenged fish were negative. Detection of the bacteria by culture on $\mathrm{CHAH}$ agar media was possible in $58 \%$ of the dead fish and $38 \%$ of the survivors. The mean amount of F. noatunensis subsp. orientalis GE detected in spleens from dead fish analyzed by real-time PCR was $1.8 \times 10^{5} \mathrm{GE} \mathrm{mg}^{-1}$ of spleen tissue, while surviving fish presented a mean amount of $1.5 \times 10^{3} \mathrm{GE} \mathrm{mg}^{-1}$ of spleen tissue.

\section{DISCUSSION}

In the present study, we developed a TaqMan realtime quantitative PCR assay for the rapid identification and quantification of the emergent fish pathogen Francisella noatunensis subsp. orientalis. The development of this highly sensitive diagnostic method will enhance the diagnosis of this fastidious organism, which could be present at low levels in fish tissue and may require specialized media in which to grow; this organism may possibly be overgrown by secondary contaminants following attempts at primary isolation. Molecular diagnostic tests have been used to alleviate some of these problems and have been used along with DNA sequencing to give definitive diagnosis in complicated cases (Hsieh et al. 2006, Mauel et al. 2007, Soto et al. 2009a). As with many other diagnostic techniques, conventional PCR has certain limitations. It is time consuming, the results are based on band size discrimination and are measured at EndPoint (plateau), and there is often low sensitivity, low resolution, and no quantification. On the other hand, real-time PCR collects data in the exponential phase, has increased dynamic range of detection, and has reduced time in post PCR processing (Espy et al. 2006). It is not surprising that the technique has increasingly been used in the past $5 \mathrm{yr}$ for the detec- tion and quantification of important human and veterinary fastidious bacterial pathogens like Mycobacterium tuberculosis, F. tularensis, Bacillus anthracis, etc. (Bode et al. 2004, Kocagoz et al. 2005, Takahashi et al. 2007, Tomaso et al. 2007, Abril et al. 2008). The disadvantages of real-time PCR include the cost of the assay, which is substantially higher than that of either microscopy or conventional PCR, and the need for specialized real-time PCR analyzers, which are currently beyond the means of many laboratories. Also, the presence of specific bacterial DNA in a tissue sample may not always indicate disease or viable bacteria. Thus, it is important to correlate the findings of this molecular technique with the history and macroand microscopic findings of the clinical isolate (Bode et al. 2004, Espy et al. 2006, Kocagoz et al. 2005, Takahashi et al. 2007, Tomaso et al. 2007, Abril et al. 2008).

The assay developed in this study is directed against the previously identified iglC gene in Francisella noatunensis subsp. orientalis isolate LADL 07-285A (Soto et al. 2009b). The homologous gene in F. tularensis subspecies has been found to be upregulated in vivo and in vitro when the bacterium is infecting and colonizing macrophages and has been found to be essential for the survival of the bacterium inside the cells (Nano et al. 2004, Santic et al. 2005).

The specificity of the TaqMan probe real-time iglC PCR assay was assessed with other strains of the genus Francisella (F. tularensis subsp. novicida U112 and F. tularensis subsp. holarctica LVS), clinically relevant cold- and warm-water fish pathogens ( $F$. noatunensis subsp. noatunensis, Streptococcus spp., Edwardsiella spp., Aeromonas spp., Vibrio spp., Mycobacterium spp., Photobacterium spp., etc.), and non-infected tilapia splenic tissue. After 40 cycles, DNA samples from these strains failed to show amplification using the real-time PCR assay, and the assay showed no 
cross reaction of the chosen primers and probe with fish tissue or opportunistic fish pathogens listed above. This is particularly important with francisellosis, because moribund and dead fish are commonly found with secondary infections, and attempts to isolate Francisella spp. can be very difficult owing to the fastidious nature of the organism. There is evidence that the presence of other bacteria in clinical specimens may inhibit the growth of Francisella spp. and may impair the ability to isolate F. tularensis (Petersen \& Schriefer 2005). The high specificity achieved by the TaqMan real-time PCR assay did not amplify the closely related cold-water pathogen $F$. noatunensis subsp. noatunensis, but it did amplify representative $F$. noatunensis subsp. orientalis isolates recovered from warm-water cultured tilapia and striped bass. We have previously described that after comparison of the $16 \mathrm{~S}$ ribosomal RNA sequence, the $F$. noatunensis subsp. orientalis LADL 07-285A and F. noatunensis subsp. noatunensis shared more than 99\% homology, but when the iglC genes were compared, the cod and the tilapia isolates shared only $\sim 90 \%$ homology, making this gene a more specific target to differentiate between similar fish pathogens (Soto et al. 2009b). The differences found between the iglC sequences make the present assay specific for the F. noatunensis subsp. orientalis isolates.

The sensitivity limit of the assay was found to be $\sim 50$ fg of DNA (equivalent to 25 GE or CFU) of Francisella noatunensis subsp. orientalis. In this study we used different approaches to verify that our DNA extraction methodology and the real-time PCR assay did not interfere with the results obtained in the assay. After suspending viable live bacteria in tilapia tissue homogenates and in PBS, performing CFU counts in $\mathrm{CHAH}$, extracting the DNA under the same conditions, and running the assay, we found that fish tissue did not negatively affect the real-time PCR detection or quantification of F. noatunensis subsp. orientalis.

When experimentally infected tilapia were used to simulate wild epizootics, the real-time PCR assay enabled detection of the bacterium in all the dead, moribund, and surviving fish $30 \mathrm{~d}$ post challenge, whereas it was possible to isolate the bacteria by conventional culturing on agar plates in only $58.8 \%$ (10 of 17) of dead and moribund fish, and in 38\% (5 of 13) of the survivor fish $30 \mathrm{~d}$ post challenge. The presence of secondary contaminants like Aeromonas spp. was greatly reduced by the use of selective media $(\mathrm{CHAH}$ with addition of polymixin B and ampicillin) when plating tissue from autolytic fish at necropsy. The TaqMan probe real-time PCR assay also allowed us to quantify the amount of GE of the bacterium in infected tilapia spleen, thus revealing a 2-fold higher amount of GE in dead tilapia spleen than in survivors.
In conclusion, we have developed an iglC-based TaqMan real-time PCR assay with high sensitivity and specificity for the detection and quantification of the emergent warm-water fish pathogen Francisella noatunensis subsp. orientalis. The assay can be used not only as a rapid diagnostic test for francisellosis but also as a research tool for bacterial persistence, drug therapy efficacy, epidemiological studies, screening of broodstock fish, and detection of reservoirs for infection.

Acknowledgements. We thank Dr. Anne-Berit Olsen from the National Veterinary Institute, Bergen, Norway, and Dr. John Hansen from the Interdisciplinary Program in Pathobiology, University of Washington, Seattle, WA, USA, for sharing some of the strains used in the study. We also thank Dr. B. Arulanandam and Dr. J.-J. Yu, from the Department of Biology, University of Texas at San Antonio, for sharing some of the DNA used in this study.

\section{LITERATURE CITED}

Abril C, Nimmervoll H, Pilo P, Brodard I and others (2008) Rapid diagnosis and quantification of Francisella tularensis in organs of naturally infected common squirrel monkeys (Saimiri sciureus). Vet Microbiol 127:203-208

Balcázar JL, Vendrell D, de Blas I, Ruiz-Zarzuela I, Gironés O, Múzquiz JL (2007) Quantitative detection of Aeromonas salmonicida in fish tissue by real-time PCR using selfquenched, fluorogenic primers. J Med Microbiol 56: 323-328

Barker JR, Klose KE (2007) Molecular and genetic basis of pathogenesis in Francisella tularensis. Ann NY Acad Sci 1105:138-159

Birkbeck TH, Bordevik M, Frøystad MK, Baklien ^̊ (2007) Identification of Francisella sp. from Atlantic salmon, Salmo salar L., in Chile. J Fish Dis 30:505-507

Bode E, Hurtle W, Norwood D (2004) Real-time PCR assay for a unique chromosomal sequence of Bacillus anthracis. J Clin Microbiol 42:5825-5831

Brotcke A, Weiss DS, Kim CC, Chain P, Malfatti S, Garcia E, Monack DM (2006) Identification of MglA-regulated genes reveals novel virulence factors in Francisella tularensis. Infect Immun 74:6642-6655

> de Bruin OM, Ludu JS, Nano FE (2007) The Francisella pathogenicity island protein IglA localizes to the bacterial cytoplasm and is needed for intracellular growth. BMC Microbiol 7:1-10

Espy MJ, Uhl JR, Sloan LM, Buckwalter SP and others (2006) Real-time PCR in clinical microbiology: applications for routine laboratory testing. Clin Microbiol Rev 19:165-256

Euzéby J (2009) List of new names and new combinations previously effectively, but not validly, published. Validation List No. 128. Int J Syst Evol Microbiol 59:1555-1556

> Felsenstein J (1985) Confidence limits on phylogenies: an approach using the bootstrap. Evolution 39:783-791

Fujita O, Tatsumi M, Tanabayashi K, Yamada A (2006) Development of a real time PCR assay for detection and quantification of Francisella tularensis. Jpn J Infect Dis 59:46-51

Getchell RG, Groocock GH, Schumacher VL, Grimmett SG, Wooster GA, Bowser PR (2007) Quantitative polymerase chain reaction assay for largemouth bass virus. J Aquat Anim Health 19:226-233

Golovliov I, Ericsson M, Sandstrom G, Tarnvik A, Sjostedt A (1997) Identification of proteins of Francisella tularensis 
induced during growth in macrophages and cloning of the gene encoding a prominently induced 23-kilodalton protein. Infect Immun 65:2183-2189

Griffin MJ, Wise DJ, Camus AC, Mauel MJ, Greenway TE, Pote LM (2008) A real-time polymerase chain reaction assay for the detection of the myxozoan parasite Henneguya ictaluri in channel catfish. J Vet Diagn Investig 20:559-566

Hsieh CY, Tung MC, Tu C, Chang CD, Tsai SS (2006) Enzootics of visceral granulomas associated with Francisella-like organism infection in tilapia (Oreochromis spp.). Aquaculture 254:129-138

Hsieh CY, Wu ZB, Tung MC, Tsai SS (2007) PCR and in situ hybridization for the detection and localization of a new pathogen Francisella-like bacterium (FLB) in ornamental cichlids. Dis Aquat Org 75:29-36

Kamaishi T, Fukuda Y, Nishiyama M, Kawakami H, Matsuyama T, Yoshinaga T, Oseko N (2005) Identification and pathogenicity of intracellular Francisella bacterium in three-line grunt Parapristipoma trilineatum. Fish Pathol 40:67-71

Kay W, Petersen BO, Duus JØ, Perry MB, Vinogradov E (2006) Characterization of the lipopolysaccharide and $\beta$ glucan of the fish pathogen Francisella victoria. FEBS J 273:3002-3013

Kidd L, Maggi R, Diniz PPVP, Hegarty B, Tucker M, Breitschwerdt E (2008) Evaluation of conventional and realtime PCR assays for detection and differentiation of spotted fever group Rickettsia in dog blood. Vet Microbiol 129:294-303

Kocagoz T, Saribas Z, Alp A (2005) Rapid determination of rifampin resistance in clinical isolates of Mycobacterium tuberculosis by real-time PCR. J Clin Microbiol 43: 6015-6019

Lai XH, Golovliov I, Sjostedt A (2004) Expression of IglC is necessary for intracellular growth and induction of apoptosis in murine macrophages by Francisella tularensis. Microb Pathog 37:225-230

- Lauriano CM, Barker JR, Yoon SS, Nano FE, Arulanandam BP, Hassett DJ, Klose KE (2004) MglA regulates transcription of virulence factors necessary for Francisella tularensis intraamoebae and intramacrophage survival. Proc Natl Acad Sci USA 101:4246-4249

Mauel MJ, Soto E, Moralis JA, Hawke J (2007) A piscirickettsiosis-like syndrome in cultured Nile tilapia in Latin America with Francisella spp. as the pathogenic agent. J Aquat Anim Health 19:27-34

> Mikalsen J, Colquhoun DJ (2009) Francisella asiatica sp. nov. isolated from farmed tilapia (Oreochromis sp.) and elevation of Francisella philomiragia subsp. noatunensis to species rank as Francisella noatunensis comb. nov., sp. nov. Int J Syst Evol Microbiol, doi:10.1099/ijs.0.002139-0

Mikalsen J, Olsen AB, Tengs T, Colquohoun DJ (2007) Francisella philomiragia subsp. noatunensis subsp. nov., isolated from farmed Atlantic cod (Gadus morhua L.). Int J Syst Evol Microbiol 57:1960-1965

Nano FE, Schmerk C (2007) The Francisella pathogenicity island. Ann NY Acad Sci 1105:122-137

> Nano FE, Zhang N, Cowley SC, Klose KE and others (2004) A Francisella tularensis pathogenicity island required for intramacrophage growth. J Bacteriol 186:6430-6436

Nylund A, Ottem KF, Watanabe K, Karlsbakk E, Krossøy B (2006) Francisella sp. (family Francisellaceae) causing mortality in Norwegian cod (Gadus morhua) farming. Arch Microbiol 185:383-392

Olsen AB, Mikalsen J, Rode M, Alfjorden A and others (2006) A novel systemic granulomatous inflammatory disease in farmed atlantic cod, Gadus morhua L., associated with a bacterium belonging to the genus Francisella. J Fish Dis 29:307-311

Ostland VE, Stannard JA, Creek JJ, Hedrick RP, Ferguson HW, Carlberg JM, Westerman ME (2006) Aquatic Francisella-like bacterium associated with mortality of intensively cultured hybrid striped bass Morone chrysops $\times M$. saxatilis. Dis Aquat Org 72:135-145

> Ottem KF, Nylund A, Karlsbakk E, Friis-Møller A, Krossøy B, Knappskog D (2007) New species in the genus Francisella (Gammaproteobacteria; Francisellaceae); Francisella piscicida sp. nov. isolated from cod (Gadus morhua). Arch Microbiol 188:547-550

Ottem KF, Nylund A, Isaksen TE, Karlsbakk E, Bergh O (2008) Occurrence of Francisella piscicida in farmed and wild Atlantic cod, Gadus morhua L., in Norway. J Fish Dis 31:525-534

Ottem KF, Nylund A, Karlsbakk E, Friis-Møller A, Kamaishi T (2009) Elevation of Francisella philomiragia subsp. noatunensis Mikalsen et al. (2007) to Francisella noatunensis comb. nov. [syn. Francisella piscicida Ottem et al. (2008) syn. nov.] and characterization of Francisella noatunensis subsp. orientalis subsp. nov., two important fish pathogens. J Appl Microbiol 106:1231-1243

- Panangala VS, Shoemaker CA, Klesius PH (2007) TaqMan real-time polymerase chain reaction assay for rapid detection of Flavobacterium columnare. Aquac Res 38:508-517

> Petersen JM, Schriefer ME (2005) Tularemia: emergence/ re-emergence. Vet Res 36:455-467

Saitou N, Nei M (1987) The neighbor-joining method: a new method for reconstructing phylogenetic trees. Mol Biol Evol 4:406-425

Santic M, Molmeret M, Klose KE, Jones S, Kwaik YA (2005) The Francisella tularensis pathogenicity island protein $\mathrm{IglC}$ and its regulator $\mathrm{MglA}$ are essential for modulating phagosome biogenesis and subsequent bacterial escape into the cytoplasm. Cell Microbiol 7:969-979

Soto E, Hawke J, Fernandez D, Morales JA (2009a) Francisella sp., an emerging pathogen of tilapia (Oreochromis niloticus) in Costa Rica. J Fish Dis 32:713-722

> Soto E, Fernandez D, Hawke J (2009b) Attenuation of the fish pathogen Francisella sp. by mutation of the iglC gene. J Aquat Anim Health 21:140-149

> Suzuki K, Sakai DK (2007) Real-time PCR for quantification of viable Renibacterium salmoninarum in chum salmon Oncorhynchus keta. Dis Aquat Org 74:209-223

Takahashi T, Tamura M, Takahashi SN, Matsumoto K and others (2007) Quantitative nested real-time PCR assay for assessing the clinical course of tuberculous meningitis. J Neurol Sci 255:69-76

Tamura K, Dudley J, Nei M, Kumar S (2007) MEGA4: Molecular Evolutionary Genetics Analysis (MEGA) software version 4.0. Mol Biol Evol 24:1596-1599

Tomaso H, Scholz HC, Neubauer H, Al DS and others (2007) Real-time PCR using hybridization probes for the rapid and specific identification of Francisella tularensis subspecies tularensis. Mol Cell Probes 21:12-16 
Appendix 1. Evolutionary relationships of the genus Francisella on partial iglABCD and iglC sequences

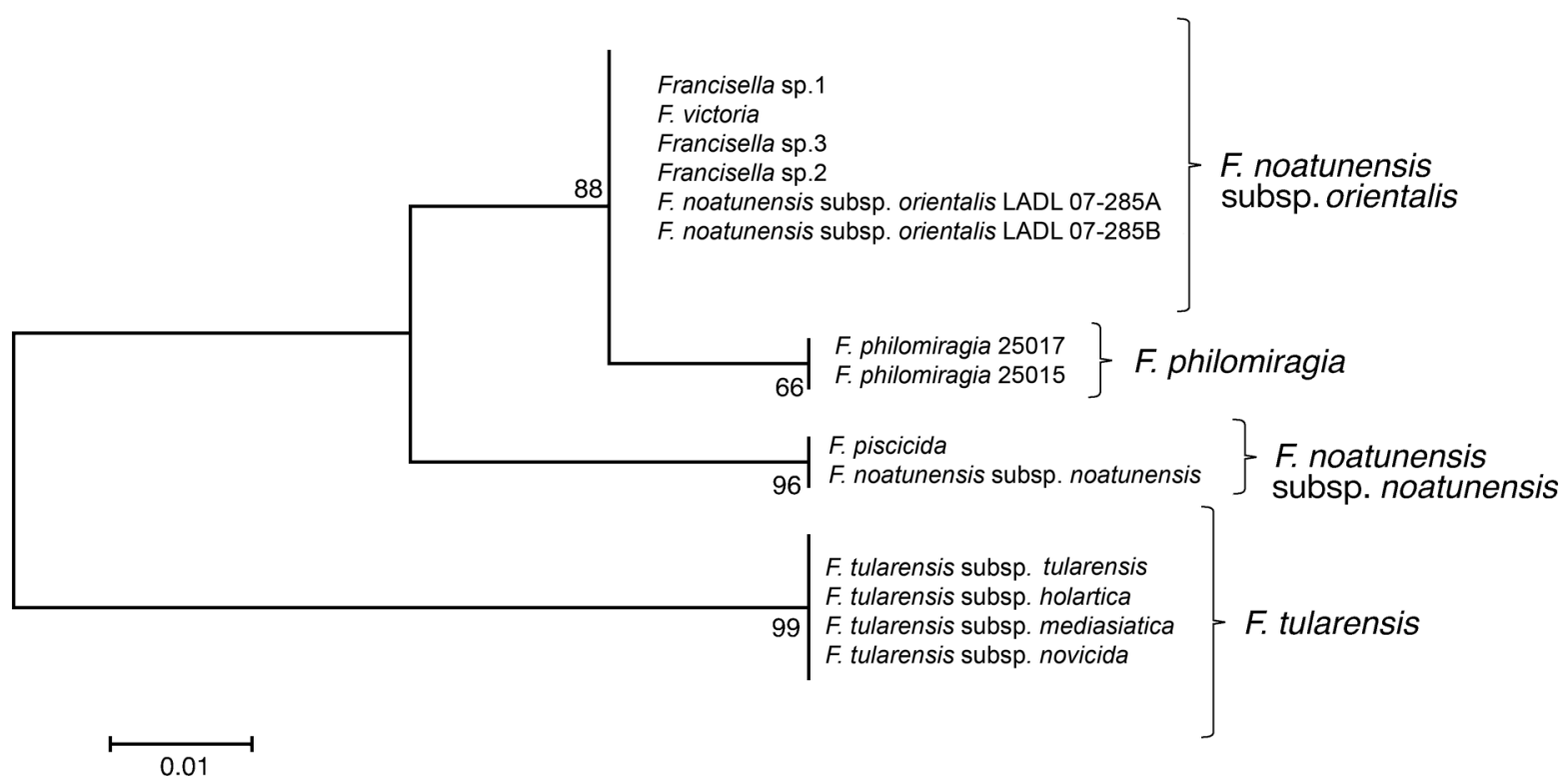

Fig. A1. Evolutionary relationships of 14 members of the genus Francisella based on partial iglABCD sequences. The evolutionary history was inferred using the neighbor-joining method (Saitou \& Nei 1987). The optimal tree with the sum of branch length = 0.14285714 is shown. The tree is drawn to scale, with branch lengths in the same units as those of the evolutionary distances used to infer the phylogenetic tree. Codon positions included were 1st+2nd+3rd+Noncoding. All positions containing gaps and missing data were eliminated from the data set (complete deletion option). There were a total of 70 positions in the final data set.

Phylogenetic analyses were conducted in MEGA 4 (Tamura et al. 2007)

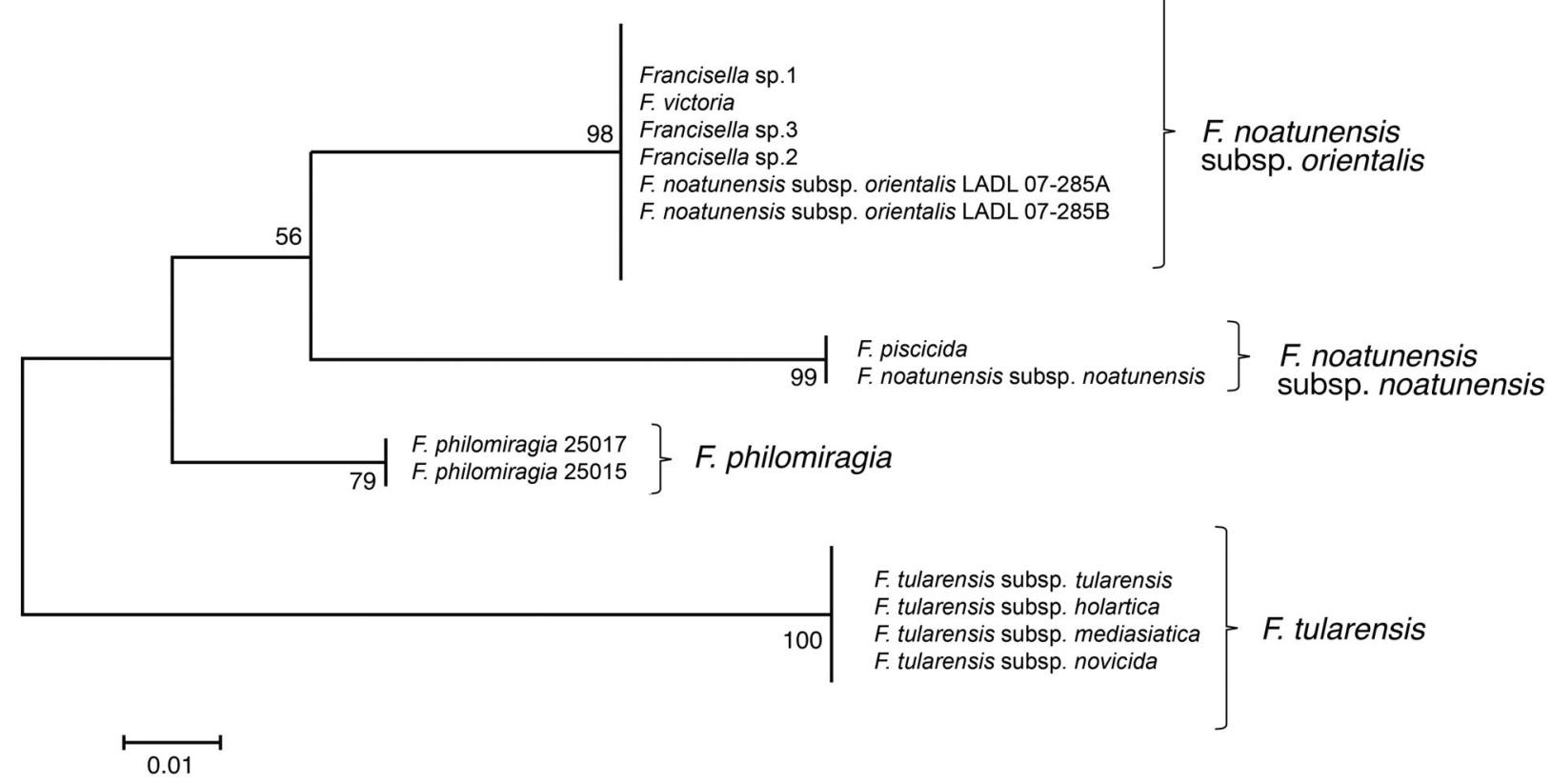

Fig. A2. Evolutionary relationships of 14 members of the genus Francisella based on partial iglC sequences. The optimal tree with the sum of branch length $=0.23571429$ is shown. The percentage of replicate trees in which the associated taxa clustered together in the bootstrap test (1000 replicates) are shown next to the branches (Felsenstein 1985). Other details as in Fig. A1 